\title{
AN EXPERIMENTAL INVESTIGATION ON PARTIAL REPLACEMENT OF FINE AGGREGATE BY USED TYRE RUBBER PARTICLES IN CONCRETE
}

\author{
S. Karthik* and T. Saranya \\ Department of Civil Engineering, SRM University, Chennai-603203(Tamil Nadu) India \\ *E-mail: karthik.sunkar17@gmail.com
}

\begin{abstract}
In recent days availability of natural resources are scarcely available and disposal of the used materials becomes a great challenge. As a result of industrialization and urbanization the usage of rubber tyre has increased drastically. The disposal of such used rubbers creates lot of environmental issues. So an attempt was made in this paper to replace fine aggregates by used tyre rubber particles in concrete. This is better advantage of saving in natural aggregates as well as it effectively uses the waste materials. For M40 grade of concrete, replacement was made in $2.5 \%, 5 \%$ and $7.5 \%$. A comparison is done in between the conventional concrete and rubber mixed concrete. Various tests for the specimens like compressive, Split tensile and flexural strength has been carried out and results were obtained. To know the binding between the ingredients of concrete SEM analysis has also been carried out. The result obtained clearly showed that the behavior of concrete at $2.5 \%$ replacement was appreciable.

Keywords: Environment, Concrete, Compression, Flexural, Mechanical Properties, Rubberized Concrete, Tyre Rubber Particles, Crumb rubber.
\end{abstract}

@ RASĀYAN. All rights reserved

\section{INTRODUCTION}

The rubber product got huge demand in day to day life across the world. The rubber which is most commonly used in the automobiles ${ }^{11}$. The usage of vehicles increases, so there is huge wastage of rubber tyres in recent days. Due to the increase in disposal of rubber by incineration and land filling that creates environmental problems like air pollution, soil infertility and massive stoke piles of used tyres ${ }^{2}$.

Usage of rubber tyre approximately 250,000 metric tons shows the record in Thailand in the year 2000 alone $^{1}$. In this $38 \%$ were vehicle tyre alone ${ }^{1}$. In India about 811 lakh metric ton of tyre rubber is produced among which about $35 \%$ were vehicle tyres alone. Now a days land filling is a common method of disposal of used tyre rubber. Nearly $32 \%$ of weight of waste tyre rubber which consists mainly of carbon black, among that carbon content is as high as 70-75 wt $\%{ }^{12}$. So the disposal of tyre rubber will create the environmental issues, hence the re usage of used tyre rubber is appreciated in the present situation ${ }^{1}$.

There usage can be done by converting the used tyre rubber into powder form and substituting it as fine aggregate in concrete and it can also be used in the road construction ${ }^{2}$ etc. High strength concrete with silica fume modified with different amount of solid particles recycled from crumbed used truck tyres ${ }^{3}$.

Tyre rubber is mainly classified depending on its size. It can be used as asphalt modifier in road surfacing, modifier in plastics and soil treatments etc.

There are number of applications by using this scrap tyres making into rubber powder ${ }^{5,6}$. So this tyre rubber can be replaced as natural aggregates in the concrete which are scarcity in the present scenario. Tyre rubber can be replaced as partially but not fully which may effects on the strength ${ }^{7,8}$. Tyre rubber is term is usually refer to recycled rubber from automotive and truck scrap tyres.

It shows from the experimental study to know the engineering properties of a concrete mix using tyre rubber particle as fine aggregate substitutes and bonding between the particles by using the SEM analysis. This study explains the strength characteristics of the rubberized concrete mix and its comparison at different percentage replacement. 


\section{Materials Used}

\section{EXPERIMENTAL}

The general properties of the concrete are tested and to know the basic properties of the concrete material have satisfies the grade strength. In order to replace the amount of fine aggregate in normal concrete by using the waste material(tyre rubber powder), the materials used are cement, sand, coarse aggregate, tyre rubber and water. Sand which passes in between $4.75 \mathrm{~mm}$ and $0.15 \mathrm{~mm}$ in size is used for this project. Coarse aggregate which is irregular broken stone or naturally occurring rounded gravel of size $20 \mathrm{~mm}$ is used. Tyre rubber of 30 mesh is used for the substitution of fine aggregate.

\section{Mix Proportion}

The grade of concrete used in this paper is M40 and the mix proportion of the grade is 1:0.44:1.53:2.65(cement: water: fine aggregate: coarse aggregate). In case of rubberized concrete, the natural sand is replaced by tyre rubber particle at an equal amount of $2.5 \%, 5 \%$, and $7.5 \%$ by volume.

\section{Details of Testing}

Three various tests were done at the department of civil engineering, SRM university, katankulathur, Chennai, Tamil nadu and consists of: (1) Compression test (2) Splitting Tensile test (3) Flexural test, with the help of test results SEM analysis were carried out. This test is done to know the bonding between the rubber particles and the cement particles inside the concrete specimen. If the bonding is good inside the specimen then the strength will be good and it can be used in the future projects.

\section{RESULTS AND DISCUSSION}

The conventional and tyre rubber concrete were tested to know the strength characteristics by doing the compressive strength, splitting tensile strength, flexural strength at various stages of 7,14 and 28 days respectively.

\section{Compressive Strength Test}

The concrete strength is mainly depends on strength of matrix and particle strength of the aggregates. Strength mainly depends upon the water/cement ratio. In this study fine aggregate is partially replaced with tyre rubber and tested it by using the compressive testing machine. The strength of the concrete at 7 , 14 and 28 day for various mixes under the constant water cement ratio and water curing, the results are given in the following figures- 1,2.3. It shows the increase of tyre rubber decreases the strength. In this study at $2.5 \%$ replacement of tyre rubber gives the good strength of $42.84 \mathrm{~N} / \mathrm{mm}^{2}$ at $28^{\text {th }}$ day test. It is higher than the conventional concrete of strength $41.9 \mathrm{~N} / \mathrm{mm}^{2}$. The results of $7,14,28$ days were shown in the Figure-1, Figure-2 and Figure-3.

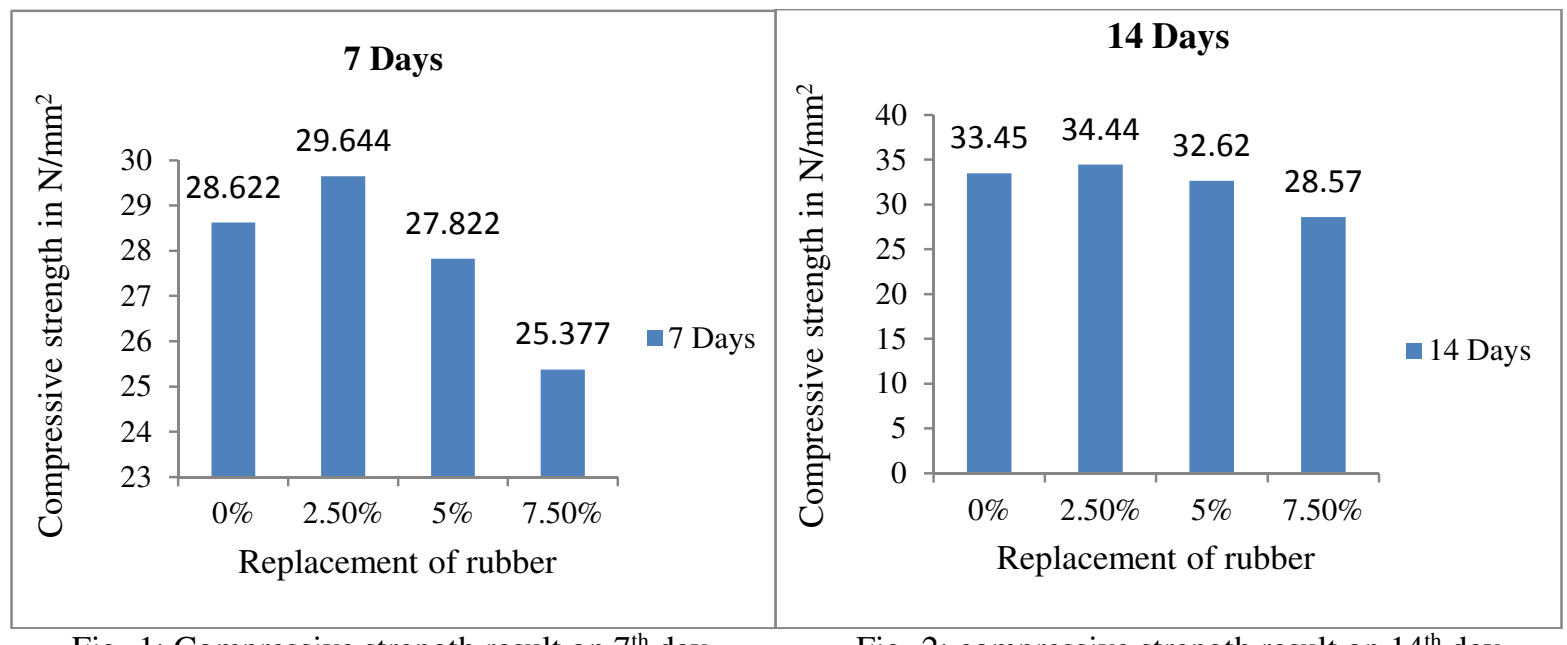

Fig.-1: Compressive strength result on $7^{\text {th }}$ day

Fig.-2: compressive strength result on $14^{\text {th }}$ day 


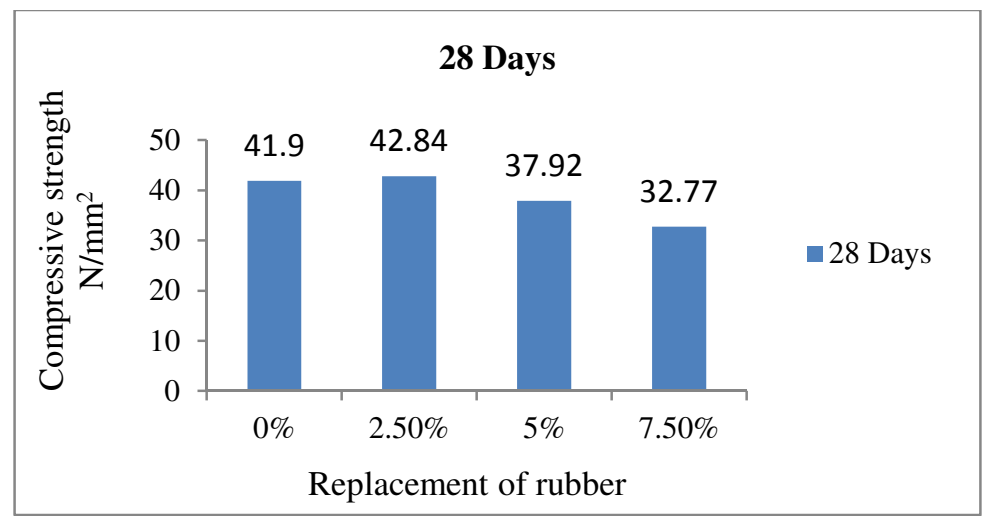

\section{Splitting tensile test}

Fig.-3: Compressive strength result on $28^{\text {th }}$ day

This test is done by replacing fine aggregate with tyre rubber powder at various ratios in normal concrete, the results on 7,14, 28 days are given in the Figures- 4, 5 and 6.The results show that on $28^{\text {th }}$ day the strength was appreciable at $2.5 \%$ replacement. By the increase of tyre rubber the strength may gradually decreases as shown in the Figures- 4, 5 and 6.

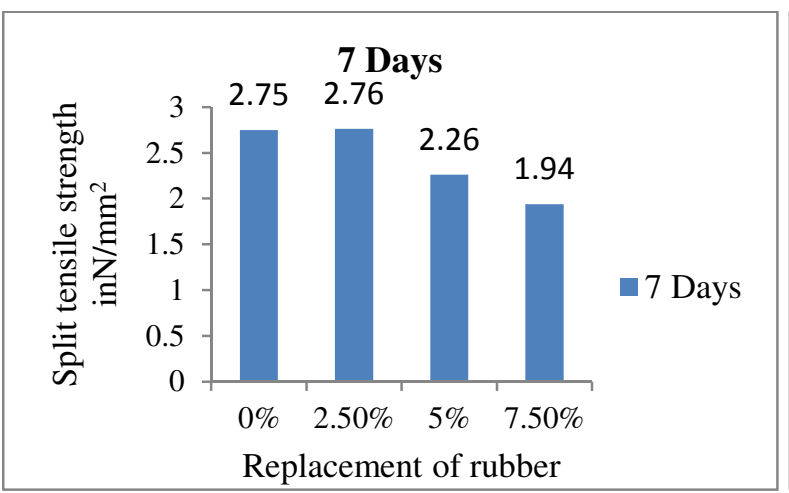

Fig.-4: Split tensile strength result on $7^{\text {th }}$ day

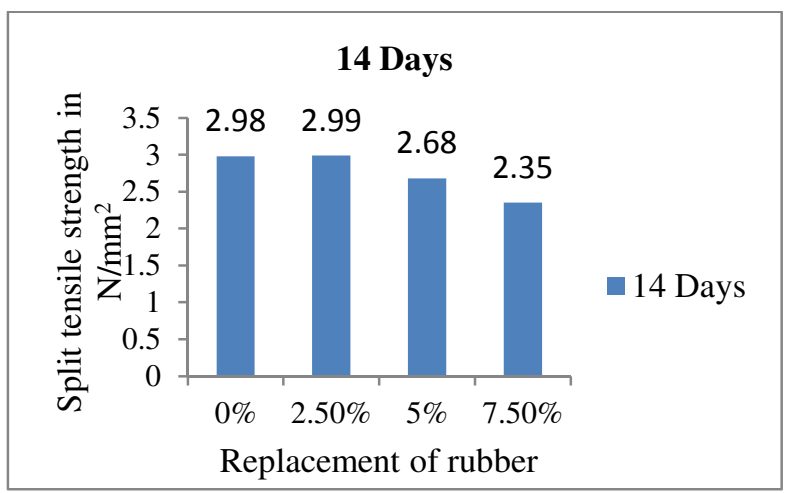

Fig.-5: Split tensile strength result on $14^{\text {th }}$ day

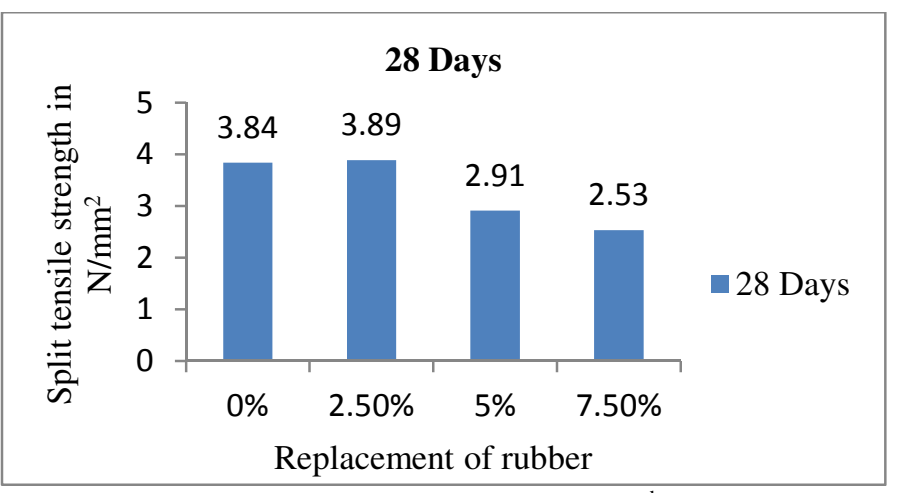

\section{Flexural Strength}

Fig.-6: Split tensile strength on $28^{\text {th }}$ day

The flexural strength for the conventional and the rubberized concrete at different proportions of $2.5 \%, 5 \%, 7.5 \%$ replacement was made. The results shows that at $2.5 \%$ replacement the strength was appreciable, and when it increases the tyre rubber that may decrease the strength which shows in the following figures. The replacement of tyre rubber of $2.5 \%, 5 \%, 7.5 \%$ results are shown in the following Figures-7,8 and 9. 


\section{Comparison on compressive strength results}

The compressive strength results which are obtained from the tests of conventional and the tyre rubber concrete by different percentage of replacement of rubber in fine aggregate by $2.5 \%, 5 \%, 7.5 \%$ replacement on $7^{\text {th }}$ day, $14^{\text {th }}$ day, $28^{\text {th }}$ day are compared in the following Figure-10. The results which are mentioned in the figure 10 tells that at $2.5 \%$ replacement of tyre rubber strength may increase, but when we increase the tyre rubber content in the concrete the strength may get decreases. The conventional concrete on $28^{\text {th }}$ day gives the strength of $41.9 \mathrm{~N} / \mathrm{mm}^{2}$. Rubberized concrete on replacement of $2.5 \%$, it gives the result of $42.84 \mathrm{~N} / \mathrm{mm}^{2}$.

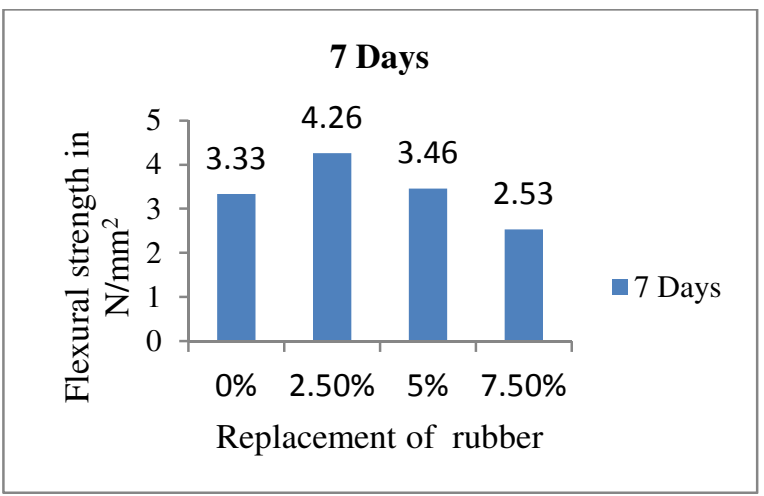

Fig.-7: Flexural strength result on $7^{\text {th }}$ day

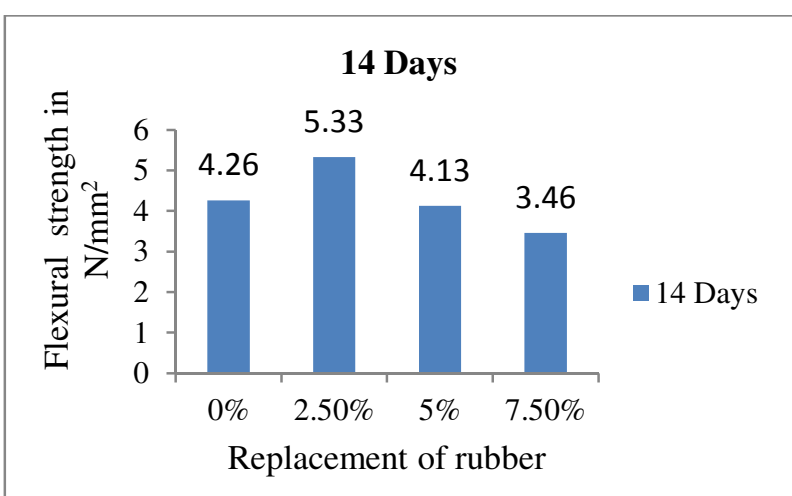

Fig.-8: Flexural strength result on $14^{\text {th }}$ day

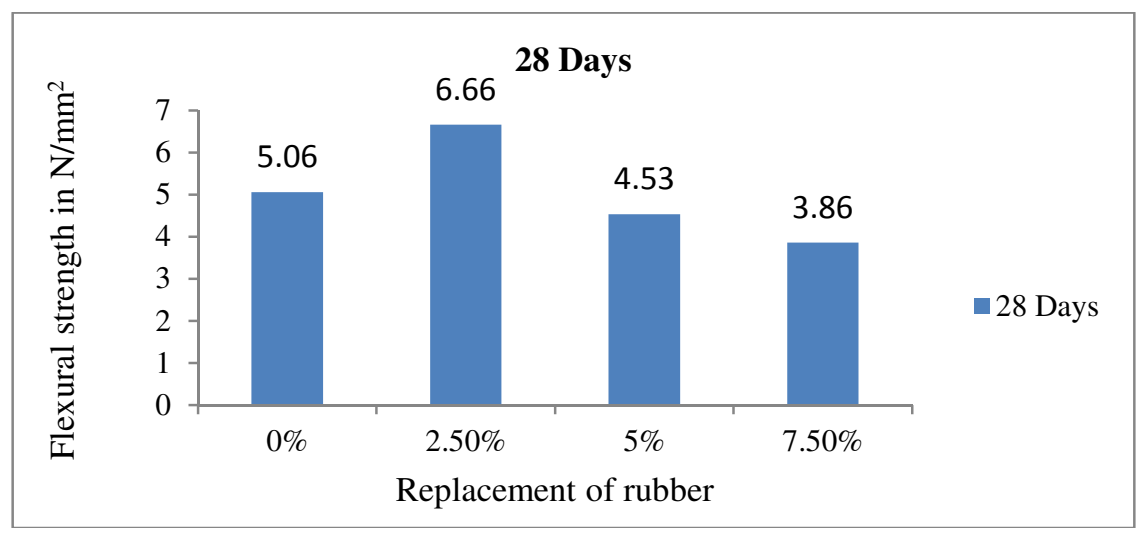

Fig.-9: Flexural strength result on $28^{\text {th }}$ day

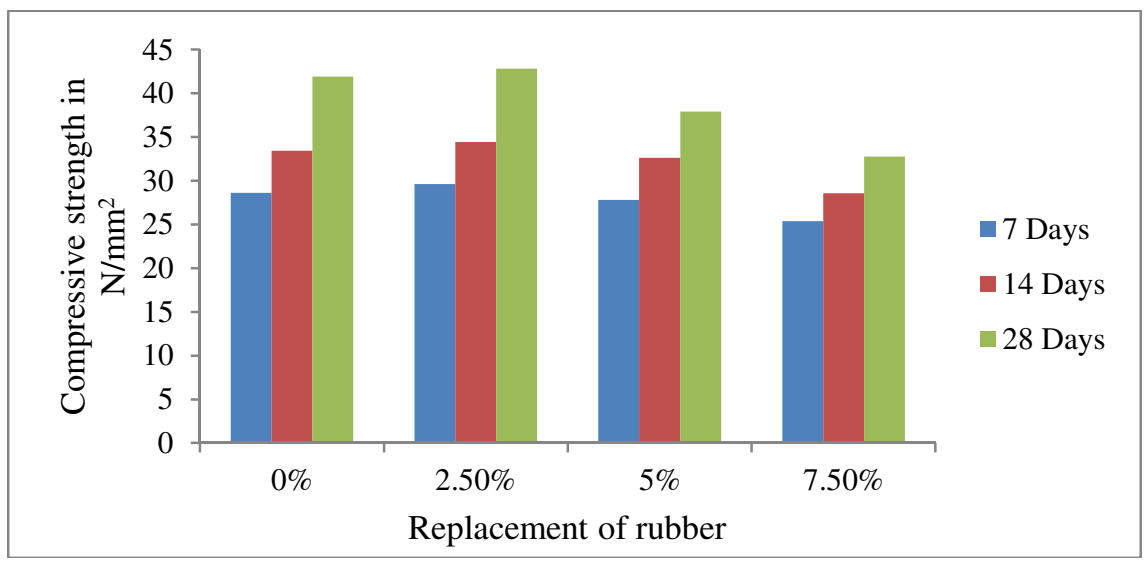

Fig.-10: Comparison on compressive strength results 


\section{Comparison on splitting tensile strength results}

The comparison was made on the split tensile strength of cylindrical specimens of conventional concrete and tyre rubber concrete at different mix ratios according to the curing period of 7, 14 and 28 days. From the Figure-11, it is clear that strength was increase on $2.5 \%$ replacement, and it gradually decreases when the rubber content was increase. The result of conventional concrete on the $28^{\text {th }}$ day is $3.84 \mathrm{~N} / \mathrm{mm}^{2}$, and when it is replaced with fine aggregate by rubber powder at $2.5 \%$ the strength will be $3.89 \mathrm{~N} / \mathrm{mm}^{2}$. It clearly tell us that on $2.5 \%$ replacement the strength will increase in this split tensile strength also.

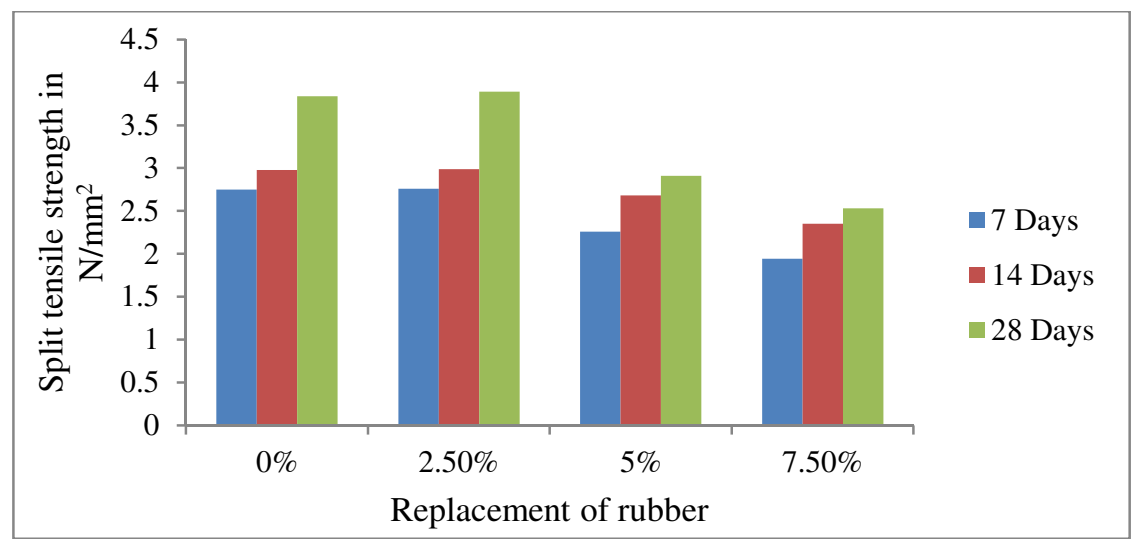

Fig.-11: Comparison on splitting tensile strength result

\section{Comparison on flexure strength results}

The comparison of flexure strength of beam of conventional concrete and rubber concrete are done in the Figure-12. The strength on $7^{\text {th }}$ day, $14^{\text {th }}$ day, $28^{\text {th }}$ day is also compared in the Figure-12. It clearly shows that on $2.5 \%$ replacement of tyre rubber the strength was appreciable.

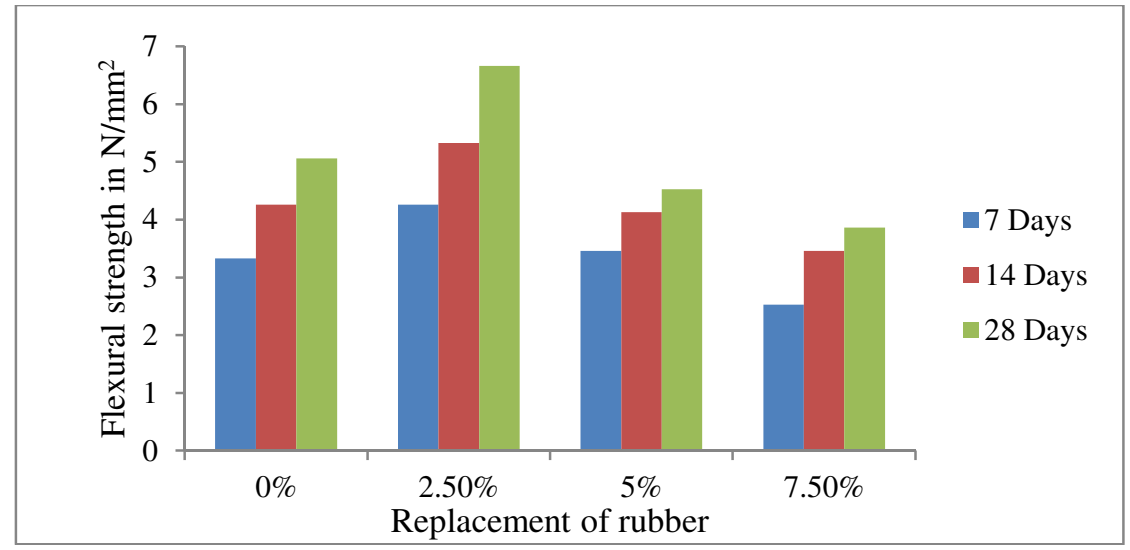

Fig.-12: Comparison on Flexural strength results

\section{Microstructure study by SEM analysis}

SEM analysis is an electron magnifying instrument which produces images through engaged light emission. SEM can scan the samples upto 1 nanometer. The samples may have many electrons which is surrounded around the particles, that electrons will exactly scanned by the scanning electron machine and it clearly shows how bonding will be inside the structure of sample. By checking the specimen and collecting specimens at different views in the scanning microscopy a picture is made which shows the clear view. The following are the different figures that are analyzed through SEM analysis with different percentage replacement of tyre rubber powder. 
RASĀYAN J. Chem.

Vol. 10 | No. 2 |415 - 422 | April - June | 2017

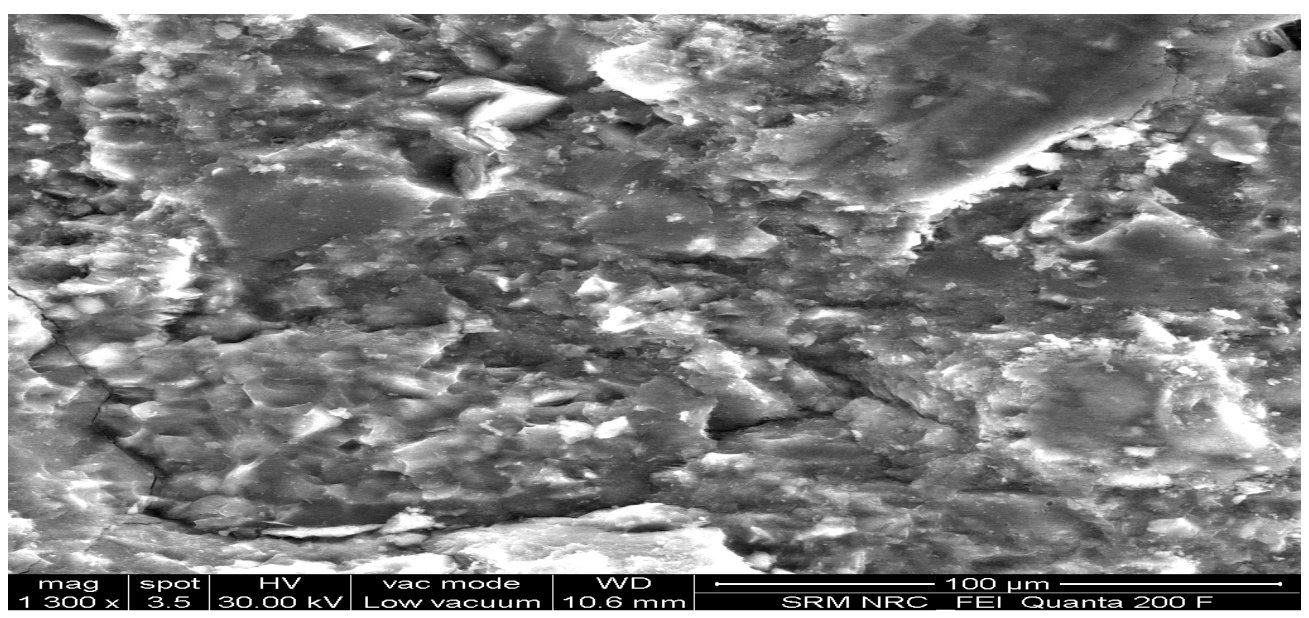

Fig.-13: SEM image of 0\% replacement

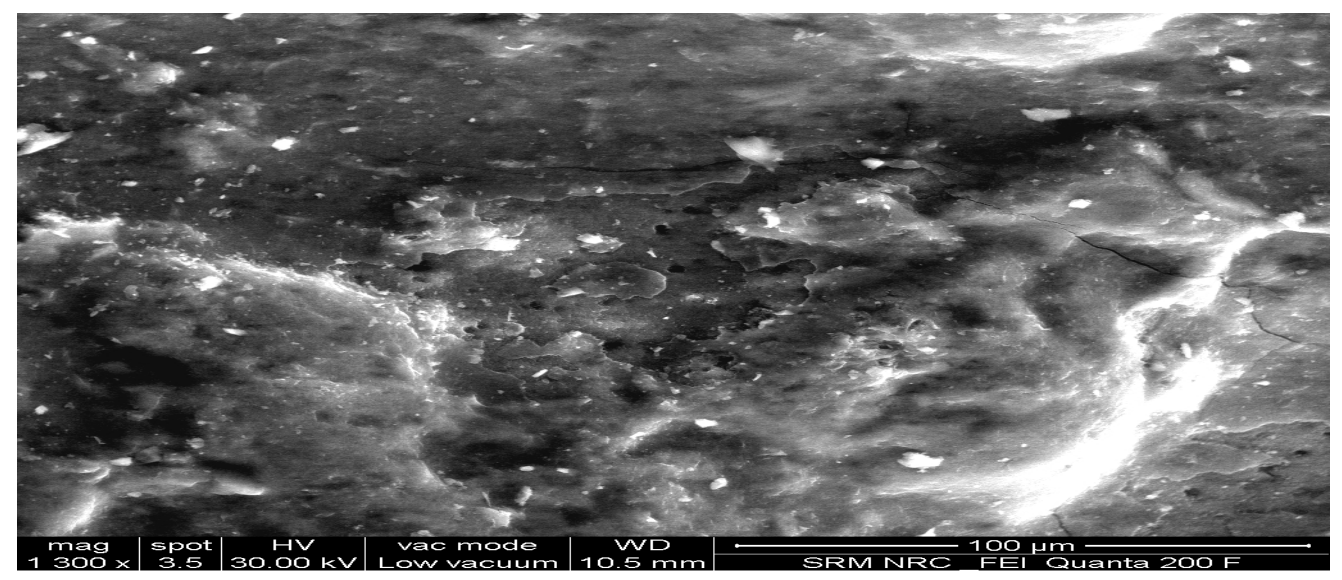

Fig.-14: SEM image of $2.5 \%$ replacement

In this SEM results we can clearly see that how the bonding occurs inside the sample of the concrete specimen. When we increase the rubber content then the bonding between rubber and other particles inside the specimen was not as good as compared to the $0 \%$ and $2.5 \%$. So if we increase the rubber content then the strength will decreases which shows clearly in this SEM analysis.

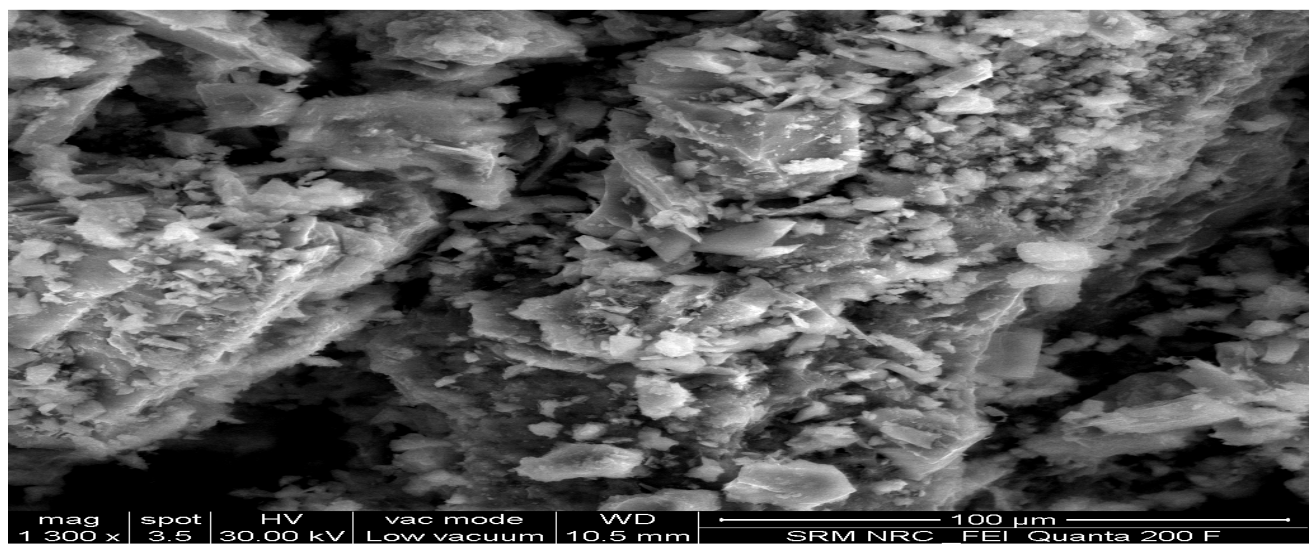

Fig.-15: SEM image of 5\% replacement 


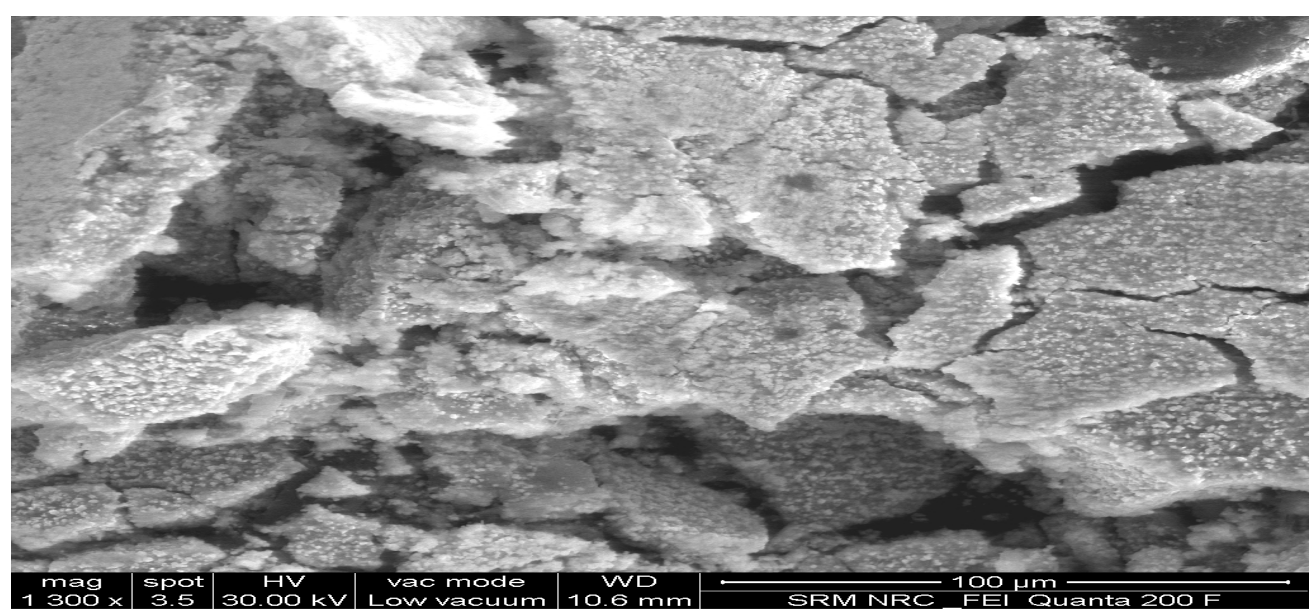

Fig.-16: SEM image of $7.5 \%$ replacement

\section{CONCLUSION}

Different experimental procedure were conducted to know the usefulness of tyre rubber powder in the concrete as a partial replacement to the fine aggregate. In this study M40 grade of concrete were designed with the water-cement ratio 0.44 and tyre rubber is replaced at different percentages of $2.5 \%, 5 \%$, and $7.5 \%$. The mix with $0 \%$ is taken as conventional concrete, and is compared with the rubberized concrete. Different tests like compressive strength, splitting tensile strength, flexural strength tests were conducted to know the strength of the concrete. And SEM analysis were also done to know how bonding is inside the concrete specimen with the tyre rubber which is partially replaced at different percentages. The following are the conclusions which were obtained from this study:

1. It is clear that tyre rubber powder can be used as a replacement to the fine aggregate up to $2.5 \%$, if the percentage is increased beyond this limit desired results were not obtained.

2. From the SEM analysis it is clear that the bonding between cement and the tyre rubber powder is good up to $2.5 \%$ and good bondage is not observed above this percentage. From the results it is suggested that by using tyre rubber we can construct the low strength required structures like pavements, agricultural purpose like fences and poles.

\section{ACKNOWLEDGEMENT}

A sincere thanks to my guide and the reference authors for making me to complete my project and to complete my paper work. The reference authors given the clear idea to approach the project work and to complete in sufficient time.

\section{REFERENCES}

1. Piti Sukontasukkul, Chalermphol Chaikaew, Construction and Building Materials 20,450(2006).

2. Eshmaiel Ganjian, Morteza Khorami, Ali Akbar Maghsoudi, Construction and Building Materials23, 1828(2009).

3. F. Hernandez-Olivares, G. Barluenga, Cement and Concrete Research 34, 109(2004).

4. F. Hernandez-Olivares, G. Barluenga, B. Parga-Landa, M. Bollati, B. Witoszek, Construction and Building Materials 21, 1918(2007).

5. H. A. Toutanji, Cement and Concrete Composites 18, 135(1996)

6. Piti Sukontasukkul, Construction and Building Materials 23, 1084(2009)

7. M. Mavroulidou, J. Figueiredo, Global NEST Journal 12, 359(2010)

8. L. Zheng, X. Sharon Huo, Y. Yuan, Construction and Building Materials 22, 939(2008)

9. N. I. Fattuhi, L. A. Clark, Construction and Building Materials 10, 229(1996) 
RASĀYAN J. Chem.

Vol. 10 | No. 2 |415 - 422 | April - June | 2017

10. Blessen Skariah Thomas, Ramesh Chandra Gupta, Pawan Kalla, Laszlo Cseteneyi, Construction and Building Materials 59, 204(2014)

11. K. Rajkumar, Premranjan, P. Thavamani, P. Jeyanthi, P. Pazhanisamy, Rasayan J. Chem. 6(2), 122(2013).

12. H. Jogarao, P. King, Y. Parasannakumar, Rasayan J. Chem. 9(2), 254(2016).

13. N. Raman, D. Sathiyanarayanan, Rasayan J. chem. 1(4), 828(2008).

[RJC-1642/2017] 